\title{
New deal for junior doctors' hours: how to achieve it
}

\author{
C J K Bulstrode, A J Muir Gray, M Anderson, C I Hawke
}

The new deal for junior doctors ${ }^{1}$ is designed to improve their hours and conditions. It is designed specifically to reduce the total number of hours worked, limit the number of hours worked in one stretch, and improve living conditions for doctors on duty. The paper looks at the approach taken in Oxford region, where the aim has been to use the new deal as an impetus to bring about changes, however radical, which will also improve the service provided and the training given to junior staff.

\section{Accommodation}

The standard of accommodation provided for most junior doctors is often poor. However, most junior doctors' right to free accommodation will disappear with the reduction in working hours, and in some hospitals the number of juniors requiring accommodation will fall once rent is payable: many already have private accommodation nearby and use the hospital accommodation only while on call. The reduced need for accommodation and the rents generated by the rest should provide resources which can be concentrated on upgrading on call rooms and any further accommodation required.

\section{Service to training ratio}

The work of junior doctors can be divided into time spent providing a service commitment and time spent being trained. There is no clear distinction between the two types of work, merely a smooth gradation from one extreme to the other. Training is more likely to occur when a consultant is present but clearly can take place when a consultant is not present. However, this is likely to be balanced by the fact that even when a consultant is present some of a junior doctor's work will be mainly service commitment. To help study the change in potential training which occurs when new duty patterns are introduced we have divided junior doctors duty hours into those in which a senior doctor is present (potential training time) and those when one is not (mainly service duties). This division provides a useful way of ensuring that a reasonable amount of training is taking place and that any changes in rota enhance rather than detract from training. Our goal has been to reduce junior doctors' hours while increasing the potential training time as a percentage of the total hours worked. Our goal for potential training time percentage is $50 \%$. This figure has been chosen because it is the ratio reached by most good training units at present.

\section{Numbers of doctors available under various shifts}

Under the new deal the work patterns for junior doctors have been divided into three types: full shift, partial shift, and on call. Full shift is appropriate for units where workload remains relatively constant day and night seven days a week. The minimum number of

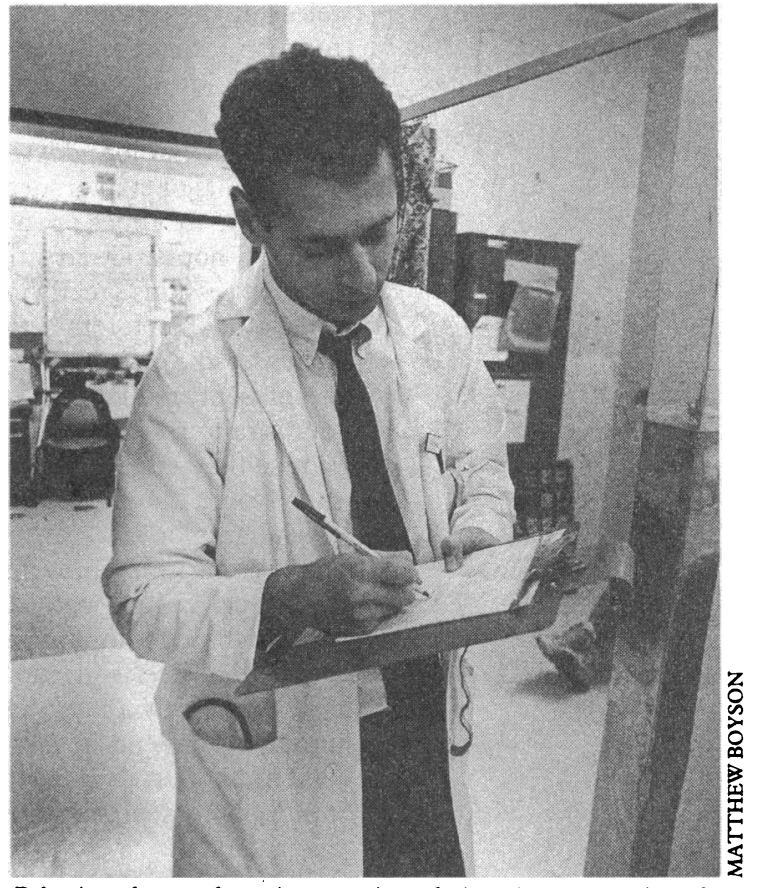

Releasing doctors from inappropriate duties gives more time for training

doctors at each tier required to run a full shift is fivethat is, four doctors to run the shift and one doctor for prospective cover. A shift organised on this basis is very unsatisfactory. Only two doctors are available for some of daylight (training) hours, and overall the potential training time percentage is low (less than $30 \%$ ). Increasing a full shift to six doctors allows three to be on duty most of the day (potential training time percentage $>50 \%$ ).

Partial shifts will be the most appropriate arrangement for most front line acute specialties that are not compelled to work a full shift. An acute unit busy enough to have adequate juniors in each tier is unlikely to be so quiet at night that an on call rota can be used. The minimum number of doctors required for a partial shift is four, including prospective cover, but the potential teaching time percentage will be less than $30 \%$. Six is the minimum number required to bring the potential training time percentage above $50 \%$.

If two units have agreed to share night cover, a partial shift is appropriate to provide that cover. If there were three senior house officers in one unit and a further three in another unit a short distance away, the potential training time percentage will be satisfactory but the number of juniors available to each unit during the day will be only two on most days and one on some.

The minimum number of doctors required for an on call rota with prospective cover is five. This gives an effective rota of one in four (the fifth being needed to cover holiday and study leave). At any one time one doctor will be on leave while the other four will be working during the day. One of these four in turn will 
provide the night time cover. The potential training time percentage is over $50 \%$, but the system requires that all work is done during standard working hours. This is unlikely to work in acute major specialties but could work well in the support specialties.

\section{Solutions to the problems}

CHANGES IN CONSULTANTS' WORK PRACTICE

The new deal has no provision to increase the number of junior doctor posts, but there is some funding for a limited number of consultant and staff grade posts. If these new senior doctors are contracted to work only during standard hours ( 9 am to $5 \mathrm{pm}$ ), the net effect is to reduce junior doctors training time by releasing them from daylight duties (potential training) to work at night and weekends (mainly service duties). Simple addition of extra senior posts without radical changes in working practices will adversely affect quality of junior doctors' training. Contracts for consultants or staff grades that include fixed sessions at non-standard times open up radical solutions to junior doctors' hours. Contracting consultants to work fixed evening sessions greatly increases the potential training time available for the junior doctors in that unit. It increases the length of time each day that consultants are present, reduces the time each day when a consultant is not present, and under some circumstances may reduce the need for junior doctors to cover that period that would have been mainly service time. Having consultants on duty at times of peak workload (often the evening) may prevent backlogs building up. This in turn can reduce work after midnight and may allow a job which might otherwise be a full shift (in which very strict hours are allowed to be worked) to be a partial shift (in which longer hours can be worked by each junior). The end result is an improved service for patient, better working conditions, and training for junior doctors, and a more cost effective service for the management.

If consultants work fixed evening sessions then a satisfactory potential training time can be provided with fewer juniors in each tier. Consultants who do agree to work evening sessions may find off duty periods during the day attractive for alternative work and leisure activities.

\section{REDUCTION OF TIERS}

Multiple tiers of duty doctors (preregistration house officer, senior house officer, registrar, senior registrar, consultant) will lead to long hours of duty being worked by doctors who are rarely if ever called. If the workload is such that more than one doctor is needed regularly, the more than one doctor at the appropriate level should be used. Reduction of tiers may be unpopular with some junior doctors as it cuts out those inefficient work practices in which juniors are paid for long hours of duty while being required to do very little work. Multi-tier on call rotas are open to abuse, expensive, inefficient, and often have poor training vaiue. The financial savings produced by rationalisation of tiers can be large and could be used to fund extra study leave, as well as for employing non-medical staff to relieve junior doctors of inappropriate duties.

\section{INAPPROPRIATE DUTIES}

Many of junior doctors' duties could be performed by non-medical staff. Examples are ward clerks, phlebotomists, and training nurses to administer intravenous drugs. The University of London has defined inappropriate duties ${ }^{2}$ and a further study has suggested that junior doctors spend up to four hours a day on duties which could better be performed by other staff (S Weaver et al, personal communication). Developing

\section{Logical plan for reduction in junior doctors' hours}

(1) Audit outpatient clinics. Identify and discharge patients being inappropriately followed up. Decide on an appropriate new patient to follow up ratio and calculate outpatient requirements if the current practice was modified to this ratio. Decide whether evening clinics would be acceptable and improve quality. Release unsupervised junior doctors from outpatient clinics and decide which clinics it would be useful for them to attend for teaching purposes. Consider appointing staff grades for service work.

(2) Arrange for management to employ appropriate staff to relieve junior doctors of inappropriate tasks (ward clerks, phlebotomists, etc).

(3) Find out how much work could be moved into standard working hours ( $9 \mathrm{am}$ to $5 \mathrm{pm}$ ) if adequate resources were provided (correct staffing for workload, on take doctor has no other duties, inappropriate duties performed by non-medical staff).

(4) Decide if routine evening emergency lists (or evening outpatient clinics) would reduce work after midnight so that the night shift could be reduced to on call or a partial shift.

(5) Rationalise tiers of juniors to provide the correct number of the appropriate seniority on duty at any given time, allowing for prospective cover for holiday and study leave on a planned basis.

(6) Arrange leave periods to be issued with the job description.

(7) From the work pattern now created decide whether your unit can work an on call (negligible work after midnight-radiology, etc), partial shift (considerably less work after midnight and at weekends than the rest of the time (surgery and general medicine), or a full shift (workload relatively constant day and night seven days a week-special care baby units, etc).

(8) Decide whether there are adequate juniors for the work pattern. If not explore amalgamation of units, rationalisation of sites, or cross cover with another specialty in the same difficulty. Alternatively decide whether to have consultants first on call (at least during the evening when emergency work may peak). Apply for an extra consultant if this route is appropriate.

(9) Check that potential teaching time is $50 \%$ or better. If not reconsider section 8 .

inappropriate duties shortens working hours and frees up time for training.

\section{OUTPATIENTS}

Junior doctors should not see outpatients unsupervised. There is little training value in this practice and those clinics which have stopped it have found a large reduction in clinic workload. Inexperienced doctors are justifiably unwilling to discharge patients from clinic, and may allow the clinic to become swamped with follow ups. Audit of what is being achieved by an outpatient appointment and the use of staff grade posts can transform the outpatient service. Junior doctors on take should have no other duties apart from dealing with emergency admissions. By freeing up the juniors during the day to see emergency patients a backlog in the evening and night can be avoided.

\section{WORK AFTER MIDNIGHT}

If the night on duty involves appreciable work after midnight then the following day should be off duty (partial or full shift), as the junior is likely to be too tired to be taught. However, in the acute services much of the work performed after midnight is carried over from the evening. Extra staff and reorganisation of resources (extra planned lists in the evening and 
following morning) may allow the service to be "put to bed" by midnight, giving juniors at least some chance of getting some sleep.

AMALGAMATION OF UNITS

Small units (less than four consultants) may experience severe problems in reducing junior doctors' hours (for all but the first stage). The alternatives to closure are to have consultants working antisocial hours by being first on call or to share on call with other units (same specialty in other hospitals or other specialties in the same hospital).

DEFAULT LEAVE PERIODS

Some of the greatest problems are created when more than one junior wishes to take leave at the same time, especially at the end of the job. Leave periods must be written into the job contract signed at the time that the job is accepted. If junior doctors wish to change their leave the onus lies with them to prevent disruption of the service.

\section{Conclusion}

The box gives a logical plan for reducing junior doctors' hours. The changes in hospital service required to bring their hours back to realistic levels will need to be radical. However, they are long overdue and provide a tremendous opportunity to improve the service far beyond the issue of junior doctors' hours.

1 NHS Management Executive. Funior doctors. The new deal. London: NHS Management Executive, 1991.

University of London. Inappropriate duties for preregistration house officers. BM7 1991;302:facing p 570 (clinical research edition).

(Accepted 30 September 1992)

\title{
Quality of life measures in health care. III: resource allocation
}

\author{
D J Spiegelhalter, S M Gore, R Fitzpatrick, A E Fletcher, D R Jones, D R Cox
}

MRC Biostatistics Unit, Institute of Public Health, Cambridge CB2 2SR DJ Spiegelhalter, senior statistician

SM Gore, senior statistician

Department of Public Health and Primary Care, Oxford OX1 1NF

R Fitzpatrick, university

lecturer in medical sociology

Royal Postgraduate Medical School, London W12 0HS

A E Fletcher, senior lecturer in epidemiology

\section{Department of} Epidemiology and Public Health, University of Leicester, Leicester

D R Jones, professor of medical statistics

Nuffield College, Oxford OX1 1NF

D R Cox, warden

Correspondence to:

Dr Spiegelhalter.

BMF 1992;305:1205-9
In our two previous papers we discussed the use of measures of health related quality of life in clinical trials and in describing the health of populations. ${ }^{2}$ We now turn to the difficult issue of using quality of life measures for allocating limited resources among competing health care programmes. We concentrate on the quality adjusted life year (QALYs) since this approach has received most attention. QALYs use an index combining changes in survival and quality of life of patients (and possibly others) to assess benefit brought about by the funded programme. For each programme this benefit can be divided by its economic cost and the resulting ratio used to help allocate resources. QALYs can be used to choose between alternative programmes for treating the same patients or, more controversially, to choose among programmes targeted at different groups.

The underlying philosophy is that rationing of resources is inevitable and so it is best that it is explicit and accountable. ${ }^{3}$ To ration effectively some measures of output from health care must be established. However, it is important to distinguish between such general issues, with which most may agree, and the actual techniques used in published studies, which have been greatly criticised. For example, Williams describes a method to assess current life expectancy and quality of life in which quality of life is assigned a value " $q$ " on a 0 to 1 scale, 1 representing perfect health and 0 representing death. ${ }^{+}$Each future year is then counted as worth $q$, with the possibility of discounting the value of future years in a similar manner to that used for future costs. The total QALYs for the group are estimated with and without the intervention, and the difference between the two estimates is a single composite measure of the marginal output of the programme.

Williams emphasised the possible role of QALY analysis in the marginal allocation of additional resources, and North Western Regional Health Authority made an early unsuccessful attempt at allocating its discretionary specialties revenue reserve fund to its district health authorities. ${ }^{5}$ However, district health authorities are now considering such schemes ${ }^{6}$ at a more basic level, and in at least one case serious attempts are being made at implementation. ${ }^{7}$ In this article we focus on British applications, although the most extreme example of a QALY type analysis is that attempted in Oregon. ${ }^{8}$ Here 714 condition treatment pairs were placed in rank order and Oregon proposed to fund them from the Medicaid budget according to those ranks; the future of this project is now, however, in doubt.

The QALY analyses arouse strong opinions. Critics have questioned the assumptions underlying the procedure, doubted the quality of the data for calculations, raised ethical objections concerning equity, and questioned whose values were relevant and whether it is reasonable to compare different numbers of different groups of people by a single index..$^{9-14}$ Supporters of the QALY approach have said that current examples of QALY analysis are not definitive, that the method is still in development, and that it is intended only as an aid to decision making rather than a strict recipe. ${ }^{15-17}$ The lack of an alternative procedure has also been emphasised. ${ }^{16}$

To clarify the arguments below we identify the stages necessary to introduce a QALY system for resource allocation. We discuss whether progress from stage to stage is technically feasible or ethically desirable, and conclude with some recommendations for the appropriate future role of QALY type analyses.

\section{Adopting a formal approach to resource allocation}

Allocating scarce resources among competing health care programmes requires judgment about best use. The box gives the stages between extreme positions of completely informal judgment and rigid adherence to a formula.

Few would propose intuition unaided by explicit information concerning costs and benefits as an ideal method of allocating resources but it describes much of current practice (stage 1). Changes in the NHS are forcing decision making to progress to consider cost and health benefits, which in turn is highlighting the lack of suitable information (stage 2). The issue arises of whether it is solely the patients' outcomes that are relevant: for children, parents of young children, and handicapped and elderly people, the impact on the family and carers may need to be considered. Most people would agree that considering data on cost and health benefits is desirable, and most would wish to progress to collecting validated data (stage 3 ).

At stage 3 we would expect to know how many 